\title{
The causes of inflation under Neo-Keynesian synthesis in Singapore: 1990-2014

\author{
Jiaxian Chen1, a
}

\author{
1 \\ School of Business, East China University of Science and Technology, Shanghai 200237 China; \\ Chenjiaxian217@outlook.com
}

Keywords: Neo-Keynesian, Adaptive Expectation, Inflation, Output gap.

\begin{abstract}
This study investigates the causes of inflation in Singapore from 1990 to 2014 since there were several upheavals according to the inflation growth rate in Singapore during these years. The paper works on the theory of Neo-Keynesian synthesis and with the use of adaptive expectations. The main objectives were to estimate the influence output gap may exert on inflation rate and to infer the policy implications of the estimated results. The study used kyock transformation to substitute expectations into Phillips Curve and employed OLS technique to estimate the relationships. The study finds that: inflation in Singapore is under adaptive expectative mechanism and output gap is positively correlated with inflation rate, so do expectations. The study concludes that in order to restrain inflation rate in an acceptable range, the controlling of output gap should be attached much importance. The study also recommends the need for policy makers to concentrate on public expectations.
\end{abstract}

\section{Introduction}

\subsection{Background of the Study}

The understanding of relationship between the economic growth and inflation is attached much importance since governments' actions will more likely to bring out an overshooting or undershooting of ultimate equilibrium if the quantitative dynamic relationship between those variables are blurry to policy makers, as statedy Guglielmo and Marinko (2011). Moreover, the relationship between output and inflation is not always the same among every country in terms of the intensity of impact and the direction of interaction. Therefore, a systematically knowledge for how inflation is affected by numerals variables is critical in coping with macroeconomic issues.

The basic framework of this paper is to trace the causes of inflation, specified to relationship between output and inflation is the Phillips curve augmented by adaptive expectation under neoKeynesian position.

\subsection{Literature Review}

One of the main indicators of inflation is the output gap, stated by Iris Claus (Mar. 2000)[1] He estimated whether output gap is a good signal of inflationary pressures specified in New Zealand. Iris stated two versions of Phillips curve, one is focus on the change in output gap and another is more concentrate on the level of it.

$$
\begin{aligned}
& \Delta \pi_{\mathrm{t}}=\alpha_{1}+\Sigma \beta_{1} \mathrm{kGAP}_{\mathrm{t}-\mathrm{k}}+\varepsilon 1 \mathrm{t} \\
& \Delta \pi_{\mathrm{t}}=\alpha_{2}+\Sigma \beta_{2} \mathrm{k} \Delta \mathrm{GAP}_{\mathrm{t}-\mathrm{k}}+\varepsilon 1 \mathrm{t}
\end{aligned}
$$

Referred to the research done by Coe and McDermott (1997)[2] which showed that both changes in output gap and the level of the output gap are equally important in Japan and Philippines, Iris intended to find out whether the conclusion remains same for New Zealand. By applying ordinary least squares (OLS) and comparing the results of different index, she found that the real results are similar to the predicted in-sample changes and finally confirmed that both the real and predicted inflation move in the same direction as output gap. Therefore, the output gap is a good factor to explain inflation. 
Basistha, A. and Nelson, C. (2007)[3] generated a simple model of output and inflation. They structured equations in state-space form using lagged auto regression analysis and exercised Kalman filter to do the trend analysis. Only used econometric model rather than applied it in real economic is the limitation of their paper.

\section{Research Methodology}

\subsection{Theoretical Framework}

This paper focuses on the traditional Phillips curve which augmented by adaptive expectation. Using the theory of adaptive expectation to generate expectations on money supply growth and fiscal deficit and then involving it into Phillips curve. The adaptive expectation is showed as:

$$
\mathrm{pt}^{\mathrm{e}}-\mathrm{p}_{\mathrm{t}-1} \stackrel{\mathrm{e}}{=} \mathrm{k}\left(\mathrm{p}_{\overline{\mathrm{t}}} \mathrm{p}_{\mathrm{t}-1} \mathrm{e}\right)
$$

Where; $\mathrm{k}$ is a constant greater than 0 , pte and $\mathrm{pt}$ are the expected and actual inflation. It can be rewrite as $\mathrm{p}_{\mathrm{t}}{ }^{\mathrm{e}}=\mathrm{k} \mathrm{p}_{\mathrm{t}-1}+(1-\mathrm{k}) \mathrm{p}_{\mathrm{t}-1}{ }^{\mathrm{e}}$. This model also shows the idea that expectations can be revised by past errors. Furthermore, when $\mathrm{k}<1$, the expected price level is determined by the deviation of the expected inflation from the real one based on past price level. We can find out that the actual inflation $\left(\mathrm{p}_{\mathrm{t}}\right)$ is now adjusted by expectation, which is different comparing to the traditional Phillips curve.

\subsection{Estimation Technique}

The estimation technique for the study includes Augmented Dickey-Fuller (ADF) and Kwiatkowski-Phliips-Schmidt-Shin (KPSS) test for unit root, the Hodrick-Prescott (HP) filter for output gap. In this study, I run all models on Ordinary Least Squares (OLS) intending to get the result of how output gap and inflation interact by assessing the final coefficients.

The processed be taken in the study will be divided into two parts:

a) Create expectations through Koyck transformation and obtain estimating equation;

b) Use the expectations obtained from the first process to estimate the Phillips Curve, check how well it fits and interpret the empirical results.

Before running the regression on fitted value of expected inflation, we should first calculate the output gap. We set up new series of logged Real Gross Domestic Product (GDP) and gain the gap under the Hodrick-Prescott (HP) filter.

\section{LNGDP $=$ LOG (GDP)}

We will get a new series data of output gap, which is the cycle from the HP filter and should be stationary. The gap here will be used in the estimation of Phillips curve that affected by both gap and expectations:

$\mathrm{INFt}=\mathrm{F}($ EPI, OUTPUTGAP)

This is explicitly parameterized and re-specified as follows:

$\mathrm{INFt}=\alpha_{0}+\alpha_{1}$ EPI $_{\mathrm{t}}+\alpha_{2}$ OUTPUT GAP $+\mu$

Since the basic concept of adaptive expectation is that the inflation expectations are obtained on the foundation of past expectations and the past expectations is still rely on the expectations of a more previous one, we adopt the Koyck transformation.

Use Koyck transformation for equation 3.23 and consider the lag one period:

$\mathrm{P}_{\mathrm{t}-1}=\alpha_{0}+\alpha_{1}\left(\lambda \mathrm{P}_{\mathrm{t}-1}+(1-\lambda) \mathrm{P}_{\mathrm{t}-2}\right)^{2}+\alpha 2 \Omega_{\mathrm{t}-1}+\mathrm{Ut}_{\mathrm{t}-1}$

Multiple the above equation by $(1-\lambda)$ :

$(1-\lambda) \mathrm{P}_{\mathrm{t}-1}=(1-\lambda) \alpha_{0}+\alpha_{1}(1-\lambda)\left(\lambda \mathrm{P}_{\mathrm{t}-1}+(1-\lambda) \mathrm{P}_{\mathrm{t}-2}\right)^{\rho}+\alpha(1-\lambda) \Omega_{\mathrm{t}-1}+(1-\lambda) \mathrm{U}_{\mathrm{t}-1}$

Re-arrange it and we get:

$(1-\lambda) \mathrm{P}_{\mathrm{t}-1}=(1-\lambda) \alpha_{0}+\alpha_{1}\left((1-\lambda) \lambda \mathrm{P}_{\mathrm{t}-1}+(1-\lambda) 2 \mathrm{P}_{\mathrm{t}-2}{ }^{\mathrm{g}}\right)+\alpha_{(1-\lambda)} \Omega_{\mathrm{t}-1}+(1-\lambda) \mathrm{U}_{\mathrm{t}-1}$

Substract from the previous equation3.23:

$$
\begin{gathered}
\mathrm{P}_{\mathrm{t}}-(1-\lambda) \mathrm{P}_{\mathrm{t}-1}=\left[\alpha_{0}-(1-\lambda) \alpha_{0}\right]+\left[\alpha_{\mathrm{f}}\left(\lambda \mathrm{P}_{\mathrm{t}}+(1-\lambda) \mathrm{P}_{\mathrm{t}-1}{ }^{\mathrm{e}}\right)-\alpha\left((1-\lambda) \lambda \mathrm{P}_{\mathrm{t}-1}+(1-\lambda) 2 \mathrm{P}_{\mathrm{t}-2}\right) \mathrm{e}\right] \\
+\left[\alpha_{2} \Omega_{\mathrm{t}}-\alpha_{2}(1-\lambda) \Omega_{\mathrm{t}-1}\right]+\left[\mathrm{U}_{\mathrm{t}}(1-\lambda) \mathrm{U}_{\mathrm{t}-1}\right]
\end{gathered}
$$

Expand it and then we get: 
$\mathrm{P}_{\mathrm{t}}-(1-\lambda) \mathrm{P}_{\mathrm{t}-1}=\left[\alpha_{0}-(1-\lambda) \alpha_{0}\right]+\alpha \lambda \mathrm{Pt}+\left[\alpha \Omega_{\mathrm{t}}-\alpha(1-\lambda) \Omega_{\mathrm{t}-1}\right]+\left[\mathrm{U}_{\mathrm{t}}(1-\lambda) \mathrm{U}_{\mathrm{t}-1}\right]$

Re-arrange it as:

$\mathrm{P}_{\mathrm{t}}-(1-\lambda) \mathrm{P}_{\mathrm{t}-1}=\lambda \alpha_{0}^{+} \alpha \lambda \mathrm{Pt}+\alpha \Omega_{\tau} \alpha(1-\lambda) \Omega_{\mathrm{t}-1}+\mathrm{V}_{\mathrm{t}}$

And then we get the autoregressive model as below :

$\mathrm{P}_{\mathrm{t}}=\lambda \alpha_{0}+\alpha \lambda \mathrm{P}_{\mathrm{t}}+(1-\lambda) \mathrm{P}_{\mathrm{t}-\mathrm{i}}+\alpha_{2} \Omega_{\tau} \alpha(1-\lambda) \Omega_{\mathrm{t}-\mathrm{t}} \mathrm{V}_{\mathrm{t}}$

Move the $\alpha 1 \lambda \mathrm{Pt}$ from the right side to left one, we get:

$\mathrm{P}_{\mathrm{t}}=\lambda /\left(1-\alpha_{1} \lambda\right) \alpha_{0}+(1-\lambda) /(1-\alpha \lambda) \mathrm{P}_{\mathrm{t}-1}+\alpha b_{2}\left(1-\alpha \lambda_{\mathrm{r}}\right) \Omega_{\mathrm{t}}(\alpha(21-\lambda)) /\left(1-\alpha \lambda_{\mathrm{t}}\right) \Omega_{\mathrm{t}-1}+1 /\left(1-\alpha \lambda_{\mathrm{l}}\right) \mathrm{V}_{\mathrm{t}}$

$\mathrm{P}=\mathrm{a}+\mathrm{b} \mathrm{P}_{\mathrm{t}-1}+\mathrm{c} \Omega_{\mathrm{t}}+\mathrm{d} \Omega_{\mathrm{-}-1}+\varepsilon \mathrm{t}$

Therefore the inflation depends on the inflation in last period, the output gap, the output gap in last period and the disturbance term.

Then, we can run the above autoregressive model and obtain the coefficients for Phillips curve, the equation specification is:

$\mathrm{INF}=(\mathrm{INF}(-1)$, OUTPUTGAP, OUTPUTGAP(-1))

This shows the new Phillips curve augmented by adaptive expectation.

In the above equation 2.5 ,

$$
a=\lambda /\left(1-\alpha_{1} \lambda\right), b=(1-\lambda) /(1-\alpha \lambda), c=\alpha_{2}(1-\alpha \lambda), d=-(\alpha(1-\lambda)) /\left(1-\alpha \lambda_{Y}\right)
$$

Thus, after estimated the Phillips Curve, we can get values for a, b, c, d respectively. Using the obtained values we can calculate the coefficients $(\alpha 0, \alpha 1, \alpha 2)$ for the permanent Phillips Curve:

$$
\mathrm{Pt}=\alpha_{0}+\alpha_{1} \mathrm{P}_{\mathrm{t}}^{\mathrm{e}}+\alpha_{2} \Omega+\mathrm{Ut}_{\mathrm{t}}
$$

Furthermore, we can get the relationship below:

$$
\mathrm{d} / \mathrm{c}=-(1-\lambda)=\lambda-1 \quad \lambda=\mathrm{d} / \mathrm{c}+1
$$

By the time, Wald test will be employed to test whether the value of $\lambda$ is significant or not. In Wald test, the null hypothesis $(\mathrm{H} 0)$ is $\mathrm{d} / \mathrm{c}+1=0$ and we use the $\mathrm{P}$ value to test it is significant or not.

\section{Analysis and Interpretation of Result}

\begin{tabular}{|c|c|c|c|c|}
\hline Variable & Coefficient & Std. Error & t-Statistic & Prob. \\
\hline $\mathrm{C}$ & 0.310637 & 0.067828 & 4.579759 & 0.0000 \\
\hline OUTPUTGAP & 8.546596 & 2.791210 & 3.061969 & 0.0028 \\
\hline OUTPUTGAP(-1) & -0.363913 & 3.025502 & -0.120282 & 0.9045 \\
\hline $\operatorname{INF}(-1)$ & 0.352927 & 0.093324 & 3.781751 & 0.0003 \\
\hline R-squared & 0.354802 & \multicolumn{2}{|l|}{ Mean dependent var } & 0.489347 \\
\hline Adjusted R-squared & 0.335051 & \multicolumn{2}{|l|}{ S.D. dependent var } & 0.610753 \\
\hline S.E. of regression & 0.498035 & \multicolumn{2}{|l|}{ Akaike info criterion } & 1.482133 \\
\hline Sum squared resid & 24.30780 & \multicolumn{2}{|l|}{ Schwarz criterion } & 1.585073 \\
\hline Log likelihood & -71.58878 & \multicolumn{2}{|l|}{ Hannan-Quinn criter. } & 1.523817 \\
\hline F-statistic & 17.96382 & \multicolumn{2}{|l|}{ Durbin-Watson stat } & 2.118387 \\
\hline Prob(F-statistic) & 0.000000 & & & \\
\hline
\end{tabular}

Table3.1 Estimation of Phillips Curve augmented by Adaptive Expectation

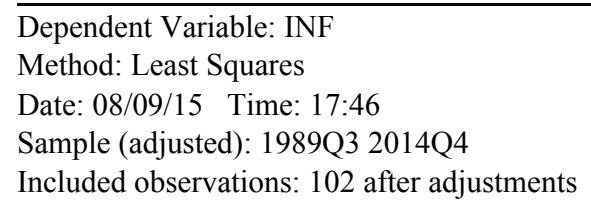

From the above estimation, we get the result shown as follows:

$$
\begin{aligned}
& \mathrm{P}_{\mathrm{t}}=0.310637+0.352927 \mathrm{P}_{\mathrm{t}-1}+8.546596 \Omega_{\mathrm{t}}+(-0.363913) \Omega_{\mathrm{t}-1} \\
& \begin{array}{lllll}
\text { St. } & (0.067828) & (2.791210) & (3.025502) & (0.093324)
\end{array}
\end{aligned}
$$

Substituting the value of coefficients into the symbols, we get four equations for $\alpha 0, \alpha 1, \alpha 2$ and $\lambda$, respectively:

$=\mathrm{a}=0.310637=\mathrm{b}=0.352927 \quad=\mathrm{c}=8.546596 \quad-=\mathrm{d}=-0.363913$

The value we got for $\alpha 0=0.039144, \alpha 1=0.918460, \alpha 2=1.031128$ and then we obtain the equation for the value of $\lambda=\mathrm{d} / \mathrm{c}+1=0.957420$. We then run the Wald test to test the significance of $\lambda$ setting the limitation of $\mathrm{C}(4) / \mathrm{C}(3)=0$, the result is as follows: 
Table 3.2 Significance test of $\lambda$

\begin{tabular}{lccc}
\hline $\begin{array}{l}\text { Wald Test: } \\
\text { Equation: Untitled }\end{array}$ & & & \\
\hline \hline Test Statistic & Value & df & Probability \\
\hline \hline t-statistic & 2.783981 & 98 & 0.0064 \\
F-statistic & 7.750553 & $(1,98)$ & 0.0064 \\
Chi-square & 7.750553 & 1 & 0.0054 \\
\hline \hline
\end{tabular}

Null Hypothesis: $\mathrm{C}(4) / \mathrm{C}(3)+1=0$

Null Hypothesis Summary:

\begin{tabular}{llc}
\hline \hline Normalized Restriction $(=0)$ & Value & Std. Err. \\
\hline \hline $1+\mathrm{C}(4) / \mathrm{C}(3)$ & 0.957420 & 0.343903 \\
\hline \hline
\end{tabular}

Delta method computed using analytic derivatives.

Under the limitation of $\lambda=0$, we find it is statistically significant (small P value) hence we have the evidence to reject the null that $\lambda=0$. Furthermore, we believe that $\lambda$ is not close to 0 and accept the value of 0.957420 and $(1-\lambda)=0.04258$.

After obtaining values of all the coefficients, we substitute them into the original Phillips Curve and adaptive expectation equation.

$$
\begin{aligned}
& \mathrm{P}_{\mathrm{t}}=0.039144+0.918460 \mathrm{P}_{\mathrm{t}}^{\mathrm{e}}+1.031128 \Omega \\
& \mathrm{P}_{\mathrm{t}}^{\mathrm{e}}=\mathrm{P}_{\mathrm{t}-1} \mathrm{e}^{\mathrm{e}}+0.957420\left(\mathrm{P}_{\mathrm{t}} \mathrm{P}_{\mathrm{t}-1}^{\mathrm{e}}\right)
\end{aligned}
$$

The first equation illustrates the Phillips Curve and the coefficients for expected inflation and output gap are 0.918460 and 1.031128 respectively, which shows the positive relationship between actual and expected inflation, as well as inflation and output gap. Specifically, one percent increase in expected inflation may lead to an increase in actual inflation by $0.9 \%$ while as the changes in output gap can exert a greater influence on actual inflation than expectation does. One percent increase of output gap may pull up the actual inflation rate by over $1 \%$ at around $1.03 \%$. The output gap is more influential than public expectations.

\section{Conclusion}

Results of this study contribute to conclusions that can be defined into two points:

a) The adaptive expectation is suitable for Singapore since the results support adaptive expectations theory.

b)Phillips Curve, which reveals a negative relationship between unemployment and inflation and a positive connection between output and inflation, is useful for Singapore's economy since the data used support the modified Phillips Curve model as well.

Moreover, to answer the proposed question in chapter one about the indications of the relationship, the output gap should be attached more importance, that is, the potential output is essential. However since the expectations as well as output gap drive inflation together, expectations should not be overlooked.

\section{References}

[1] Claus, I. Is the Output Gap a Useful Indicator of Inflation. SSRN Electronic Journal.

[2] Adams, C. and Coe, D. 1990. A Systems Approach to Estimating the Natural Rate of Unemployment and Potential Output for the United States. Staff Papers - International Monetary Fund 37(2), p. 232.

[3] Basistha, A. and Nelson, C. 2007. New measures of the output gap based on the forwardlooking new Keynesian Phillips curve. Journal of Monetary Economics 54(2), pp. 498-511.

[4] Minford, P. and Peel, D. 2002. Advanced macroeconomics. Cheltenham, UK: E. Elgar.

[5] Mehra, Y. 2004. The Output Gap, Expected Future Inflation and Inflation Dynamics: Another Look. Topics in Macroeconomics 4(1). 